\title{
ESTUDO DA VAZÃO ÓTIMA DA ADSORÇÃO DO CORANTE REATIVO AZUL 5G EM CARVÃO ATIVADO DE CASCA DE COCO DE DENDÊ
}

\author{
B. L. MOREIRA, J. A. de SOUSA, N. H. de MELO e I. C. OSTROSKI \\ Universidade Federal de Goiás, Instituto de Química \\ E-mail para contato: indianara_ostroski@ufg.br
}

\begin{abstract}
RESUMO - Este trabalho visa avaliar o efeito da vazão volumétrica para o corante reativo Azul 5G utilizando o carvão de casca de coco de dendê como adsorvente. Foram realizados ensaios em fluxo ascendente com as vazões $2,4,6$, 8,10 e $12 \mathrm{~mL} / \mathrm{min}$ para a concentração do corante de $54 \mathrm{ppm}$. A análise de parâmetros como comprimento da zona de transferência de massa, variância adimensional, razão operacional e capacidade dinâmica da coluna indicaram a condição ótima de trabalho para o sistema. O carvão se mostrou um bom adsorvente e obtiveram-se informações a respeito da capacidade de remoção do corante, essenciais para o projeto de processos de adsorção.
\end{abstract}

\section{INTRODUÇÃO}

Em indústrias têxteis é comum e necessária a utilização de corantes, que na maioria das vezes, devido à baixa fixação na fibra durante o processo de tingimento, caracterizam os efluentes com uma coloração intensa. Para evitar a poluição visual e interferências negativas nos ciclos biológicos, incluindo a fotossíntese, várias técnicas são estudas para diminuir a concentração do corante e eliminar os efluentes de forma correta, seguindo a legislação (Kunz et al, 2002).

Em particular, os processos de adsorção que utilizam carvões ativados são bastante empregados devido à versatilidade, eficiência e baixos custos de obtenção. Muitos materiais precursores de carvões ativados são obtidos de rejeitos industriais. No Brasil, é comum encontrar carvões ativados oriundos de casca de coco da Bahia e também de coco de dendê.

O processo de adsorção pode ocorrer em batelada ou em sistemas como os leitos fixos e fluidizados. A maioria dos processos de adsorção são realizados em leito fixo devido ao melhor comportamento fluidodinâmico e a maior estabilidade de tempo de residência (Davidson et al., 1985), parâmetro importante em tais processos. Os leitos fixos são particularmente interessantes devido à sua fácil operação e possibilidade de regeneração sem que o leito seja desmontado.

A utilização de sólidos adsorventes de maneira industrial pode ser feita por meio da implantação, ao final da precipitação, de leitos fixos pelos quais percorre o sobrenadante. $\mathrm{O}$ projeto de colunas deste tipo envolve o conhecimento de vários parâmetros, sem os quais a remoção pode se tornar ineficiente, mesmo que os processos de adsorção sejam favoráveis. 
Assim, o objetivo deste trabalho é estudar a vazão ótima de operação para a remoção do corante reativo Azul 5G em carvão ativado de casca de dendê. O corante foi escolhido por ser um dos mais empregados nas lavanderias industriais (Lambrecht, 2007) e o carvão por ser ainda pouco investigado para a remoção de corantes e, portanto, de grande interesse.

\section{MATERIAIS E MÉTODOS}

\subsection{Metodologia}

O adsorvente utilizado neste trabalho foi o carvão da casca do coco de dendê cedido gentilmente pela Bahiacarmo LTDA. Por peneiramento obteve-se o diâmetro médio das partículas igual a $0,725 \mathrm{~mm}$.

As soluções de corante foram preparadas a partir do corante comercial Reativo Azul 5G. Para o estudo da vazão foi utilizada a concentração de $54 \mathrm{ppm}$. A determinação da concentração de corante nas amostras foi realizada por espectroscopia no ultravioleta visível (UV/Vis), utilizando um espectrofotômetro da marca BEL - Modelo SF325NM com comprimento de onda igual a $600 \mathrm{~nm}$.

\subsection{Preparação e Operação da Coluna de Leito Fixo}

A unidade laboratorial contou com duas colunas encamisadas, para realizar o ensaio em duas vazões distintas ao mesmo tempo. As vazões estudadas foram: 2, 4, 6, 8, 10 e 12 $\mathrm{mL} / \mathrm{min}$. Os ensaios foram realizados a temperatura constante de $30^{\circ} \mathrm{C}$ por meio da conexão das colunas com o banho termostático. Os reservatórios de solução foram conectados a duas bombas peristálticas. Também foi acoplado ao sistema um reservatório de água deionizada para a lavagem do leito e a regulagem da vazão de trabalho. A Figura 1 apresenta a unidade experimental utilizada.

Figura 1 - Módulo experimental

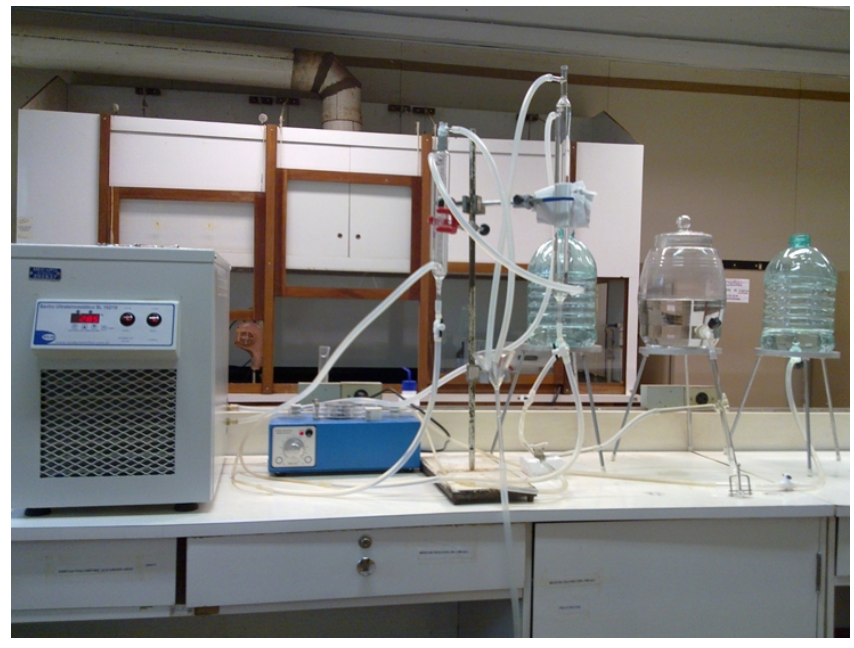

A coluna foi previamente preenchida com esferas de vidro e seguida de um chumaço de algodão bem prensado. Então elevou-se o nível de água deionizada para melhor acomodação do leito e remoção das bolhas de ar. O carvão então foi adicionado lentamente e em seguida o 
leito foi fixado com outro chumaço de algodão e a coluna foi completada com esferas de vidro até o topo. Os ensaios foram realizados em fluxo ascendente. A altura do leito foi de 2,5 $\mathrm{cm}$ e a massa de carvão usada nos ensaios foi de $1 \mathrm{~g}$. Após a regulagem da temperatura e da vazão com água deionizada, fechava-se o reservatório de água e abria o de solução de alimentação e então se iniciava o ensaio.

Amostras foram coletadas após a passagem da solução no leito fixo, em períodos de 5 minutos, com contagem iniciada após a umidificação do primeiro chumaço de algodão. As amostras foram recolhidas até haver a saturação completa do carvão.

\subsection{Estudo da Vazão Ótima de Operação}

Para a determinação da melhor vazão de trabalho, foram calculados os parâmetros de transferência de massa, a partir das curvas de ruptura (Geankoplis, 1993). O cálculo da ZTM necessita dos tempos útil $\left(t_{u}\right)$ e de saturação $\left(t_{t}\right)$ do leito. O tempo útil é obtido com o cálculo até o ponto de ruptura de coordenada $\left(C_{\mathrm{b}}, t_{\mathrm{b}}\right)$ em que $C_{\mathrm{b}}$ é a concentração da solução no tempo de ruptura $t_{\mathrm{b}}$. Geralmente, o ponto de ruptura é considerado com $5 \%$ da concentração inicial do soluto $\left(C_{\mathrm{b}}=0,05 C_{0}\right)$ (McCabe et al., 2001). O tempo de saturação é dado pela equação 1 , em que $C_{o u t}$ é a concentração de saída e $C_{0}$ é a concentração de alimentação:

$$
t_{u}=\int_{0}^{t_{b}}\left(1-\frac{C_{\text {out }}}{C_{0}}\right) d t
$$

Neste trabalho,

O tempo de saturação considera os limites de integração de zero ao tempo final do ensaio. Este é dado pela equação 2:

$$
t_{t}=\int_{0}^{\infty}\left(1-\frac{C_{\text {out }}}{C_{0}}\right) d t
$$

Com o parâmetro $\tau$ representa a fração do comprimento útil do leito até o ponto de ruptura. Este é dado por $\tau=t_{u} / t_{t}$ e a partir dele é se obtém a quantitativamente o comprimento da ZTM. Dado pela equação 3 (Geankoplis, 1993).

$$
Z T M=(1-\tau) H_{t}
$$

Outro parâmetro pertinente a ser analisado é o tempo de resistência médio $(\bar{t})$, que representa o tempo médio que o contra-íon leva até ser retido na coluna. Como descrito em Barros (2003), a equação 4 da o tempo médio para o processo de adsorção.

$$
\bar{t}=\int_{0}^{\infty} t E(t) d t
$$


Na qual $E(t)$ é a distribuição do tempo de resistência do fluido, que é calculado pela derivação da curva de ruptura do processo de troca iônica dada por $F(t)$ nas equações 5 e 6 :

$$
\begin{aligned}
& E=\frac{d F}{d t} \\
& F=\frac{C_{\text {out }}}{C_{0}}
\end{aligned}
$$

O grau de dispersão é dado pela variância adimensional $\left(\sigma^{2}\right)$, e pode ser estimado matematicamente como na distribuição do tempo de resistência em reatores reais (Barros, 2003):

$$
\sigma^{2}=\frac{\int_{0}^{\infty} t^{2} E(t) d t-(\bar{t})^{2}}{(\bar{t})^{2}}
$$

A relação entre a condição operacional ideal e a condição real é dada pela razão operacional $\left(R_{0}\right)$. Valores mais próximos de zero indicam que a condição operacional se encontra mais próxima da ideal. Esta analise fornece as condições mínimas de resistências difusionais. A razão operacional é dada pela equação 8 como mostrada em Barros (2003):

$$
R_{0}=\left|\frac{\bar{t}-t_{u}}{t_{u}}\right|
$$

Completando esta etapa dos estudos, também analisou-se a capacidade dinâmica da coluna, que é a quantidade de metal retida no leito até o ponto de ruptura. A equação 9 fornece este parâmetro (Gazola, 2004):

$$
U_{i}^{t b}=\frac{C_{0} \cdot \dot{Q}}{1000 \cdot m_{s}} \cdot t_{u}
$$

\section{RESULTADOS E DISCUSSÃO}

Por meio dos dados sobre as concentrações das amostras foi possível obter as curvas de ruptura para as diferentes vazões testadas. Observou-se que o aumento da vazão de alimentação levou a uma saturação mais rápida do adsorvente, o que já era esperado, e que concorda com os resultados de Santhy e Selvapathy (2006). As curvas de rupturas para as vazões de 2, 4, 6, 8, 10 e $12 \mathrm{~mL} / \mathrm{min}$, estão representadas na Figura 2.

Observa-se também pela Figuras 2, que os pontos de ruptura de cada ensaio também diminuem com o aumento da vazão. Tal fenômeno nem sempre ocorre. De fato, quando o material adsorvente possui poros que promovem problemas difusionais logo na abertura dos canais, os pontos de ruptura para vazões distintas são muito próximos entre si (BARROS, 2003). 
Figura 2 - Curvas de ruptura

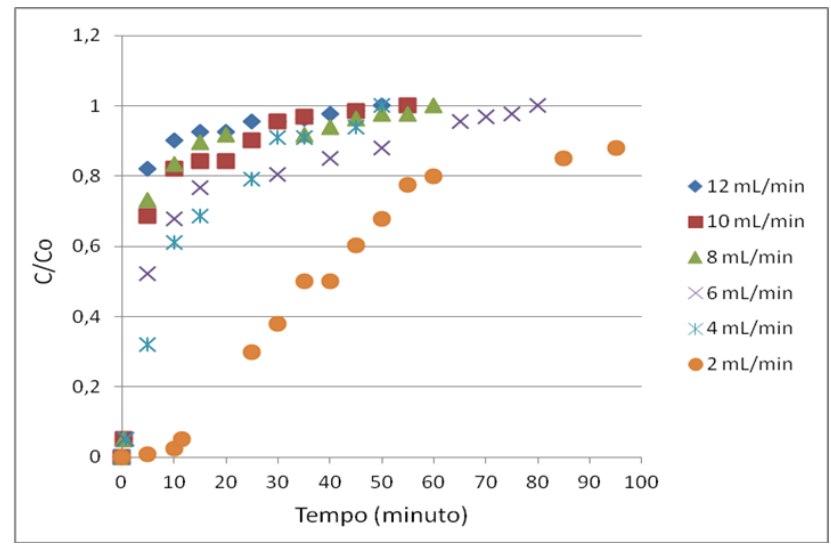

Sabe-se que o aumento da vazão resulta em redução da resistência à transferência de massa. A partir de um determinado ponto este efeito não é significativo e, portanto, existe uma vazão ótima de trabalho que pode ser determinada. Assim, o aumento da vazão propicia a diminuição do comprimento de ZTM até a vazão ótima e a partir daí, o comprimento da ZTM volta a aumentar. Acredita-se que, nestas condições, as resistências difusionais não são inversamente proporcionais ao aumento da vazão.

Na Tabela 1 são apresentados os valores calculados do comprimento da ZTM, das quantidades de corante retidas até o ponto de ruptura, considerado como o tempo equivalente à saída de 5\% (McCabe et al., 2001) da concentração da solução de alimentação, a capacidade de troca do leito, $U^{t_{b}}$, da razão operacional $R_{0}$ e da variância adimensional $\sigma^{2}$, conforme apresentados na seção 2.3.

Tabela 1 - Valores dos parâmetros para adsorção de corante azul 5G em carvão ativado da casca do coco de dendê

\begin{tabular}{ccccc}
\hline $\begin{array}{c}\text { Vazão } \\
(\mathrm{mL} / \mathrm{min})\end{array}$ & ZTM(cm) & Ro & $\sigma^{2}$ & $\mathrm{U}^{\mathrm{tb}}(\mathrm{mg} / \mathrm{g})$ \\
\hline 2 & 1,887 & 3,168 & 2,641 & \\
4 & 2,357 & 17,660 & 1,858 & 0,164 \\
6 & 2,422 & 31,527 & 2,419 & 0,151 \\
8 & 2,389 & 23,623 & 1,799 & 0,144 \\
10 & 2,363 & 20,763 & 0,895 & 0,192 \\
12 & 2,364 & 17,540 & 0,482 & 0,192 \\
\hline
\end{tabular}

Na Tabela 1, observa-se que exceto para a vazão de $2 \mathrm{~mL} / \mathrm{min}$, a ZTM ocupou quase a totalidade do leito de carvão ativado, uma vez que a altura total era de $2,5 \mathrm{~cm}$, tendo ocupado em média $95,16 \%$ do leito. 
Observa-se também que o parâmetro $U^{\text {tb }}$ é influenciado pela vazão de trabalho. Apenas para a vazão de $2 \mathrm{~mL} / \mathrm{min}$ esse valor foi satisfatório. Tal fato leva a crer que o corante necessita de um tempo de contato relativamente grande para vencer os problemas estéricos decorrentes da difusão em adsorventes com predominância de microporosos (Lambrecht, 2007).

A variância adimensional assumiu valores numa grande faixa, inclusive, valores maiores que a unidade. Esta situação pode estar relacionada com um elevado grau de dispersão no sistema, justificando portanto, valores acima da unidade. O parâmetro razão operacional $(R 0)$ assume valores grandes, indicando talvez que a faixa de vazão estudada não está totalmente adequada à seletividade para o corante.

\section{CONCLUSÃO}

Dentre a faixa de vazão estudada, observa-se que a vazão de $2 \mathrm{~mL} / \mathrm{min}$ propiciou a menor ZTM, a maior quantidade de corante retida até até o ponto de ruptura, a menor razão operacional e um elevado grau de dispersão no leito. Nesta vazão, possivelmente há a minimização das resistências difusionais devido ao alto grau de dispersão do corante na coluna. Desta forma, a vazão de $2 \mathrm{~mL} / \mathrm{min}$ foi considerada como a condição operacional ótima para este sistema.

\section{REFERÊNCIAS}

BARROS, M. A. S. D. Avaliação do Mecanismo de Troca Iônica de Cromo em Sistemas Zeolíticos. Tese de Doutorado, Universidade Estadual de Maringá - UEM, Maringá- PR, 2003.

DAVIDSON, F., CLIFT, R., HARRISON, D. Fluidization, London Academic, 1985, 746p.

GAZOLA, F. C. Construção de Isotermas a partir da Troca Iônica Dinâmica de Cromo em Colunas de Leito Fixo de Zeólitas NaX e NaY. Dissertação de Mestrado, Universidade Estadual de Maringá - UEM, Maringá - PR, 2004.

GEANKOPLIS, C.J., Transport processes and Unit Operations, 3ª edição, 1993.

KUNZ, A., PERALTA-ZAMORA, P., MORAES, S. G. et al. Novas tendências no tratamento de efluentes têxteis. Química Nova 25, 1, p. 78-82, 2002.

LAMBRECHT, R., Adsorção do corante reativo Azul 5G em carvão ativado e em xisto retortado, Dissertação de Mestrado, UEM, Maringá, 2007.

McCABE, W.L., SMITH, J.C., HARRIOT, P., Unit Operations of Chemical Engineering, McGraw-Hill International Ed., 6th ed., 2001.

SANTHY, K. e SELVAPATHY, P. Removal of reactive dyes from wastewater by adsorption on coir pith activated carbono. Bioresource Technology 97, p. 1329-1336, 2006. 